\title{
The Nature of Methadone Diversion in England: A Merseyside case study
}

\author{
Paul Duffy ${ }^{1 *}$ and Helen Baldwin ${ }^{2}$
}

\begin{abstract}
Background: Methadone maintenance treatment (MMT) is a key element in treatment for opiate addiction; however concerns about the diversion of methadone remain. More current empirical data on methadone diversion are required. This research investigated the market for diverted methadone in Merseyside, UK, in order to provide a case study which can be transferred to other areas undertaking methadone maintenance treatment on a large scale.
\end{abstract}

Methods: Questionnaires were completed (in interview format) with 886 past year users of methadone recruited both in and out of prescribing agencies. Topic areas covered included current prescribing, obtaining and providing methadone, reasons for using illicit methadone and other drug use.

Results: Large proportions of participants had obtained illicit methadone for use in the past year with smaller proportions doing so in the past month. Proportions of participants buying and being given methadone were similar. Exchange of methadone primarily took place between friends and associates, with 'dealers' rarely involved. Gender, age, whether participant's methadone consumption was supervised and whether the aims of their treatment had been explained to them fully, influenced the extent to which participants were involved in diverting or using diverted methadone.

Conclusion: Methadone diversion is widespread although drug users generally do not make use of illicit methadone regularly (every month). The degree of altruism involved in the exchange of methadone does not negate the potential role of this action in overdose or the possibility of criminal justice action against individuals. Treatment agencies need to emphasise these risks whilst ensuring that treatment aims are effectively shared with clients to ensure adherence to treatment.

Keywords: Methadone, diversion, treatment, supervision

\section{Background}

\section{Evidence of Methadone Diversion}

Whilst the effectiveness of the various models of methadone treatment has been established through international research [1-5], concerns have been expressed about the potential 'leakage' of methadone onto the 'black market' and the increased risk of harm that this entails [6-8]. The diversion of methadone has been implicated as a key contributing factor in fatal and nonfatal methadone poisonings [9-12]. The risk of street selling of methadone and its association with overdose

\footnotetext{
* Correspondence: P.Duffy1@ljmu.ac.uk

${ }^{1}$ Criminal Justice System Manager, Centre for Public Health, Liverpool John Moores University, $2^{\text {nd }}$ Floor, Henry Cotton Campus, 15-21 Webster Street, Liverpool, L3 2ET, UK

Full list of author information is available at the end of the article
}

have also been recognised by drug users being prescribed substitute medication [13].

Investigative studies in developed countries have examined the prevalence and nature of methadone diversion and illicit use [14-17]. Findings suggest methadone is used and sold illicitly at a high level relative to other prescription opioids, although the diversion of buprenorphine has also become widespread [18]. Illicit methadone use is associated with recent heroin use $[14,19,20]$ and methadone is used illicitly in conjunction with other illegal substances, such as illicit benzodiazepines [21]. It is usually administered orally however studies conducted with drug users in England and Australia reveal injecting of oral solution [22-24].

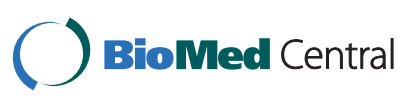


Research findings also provide insight into how the illicit market for prescription methadone is generated. Illicit methadone is commonly used as self-medication for the management of withdrawal symptoms by opiate addicted individuals not engaged in treatment $[20,25]$. It is also obtained by clients in treatment looking to supplement their own methadone prescription or replace their prescription after failing to obtain it due to missed appointments or prescription pick-ups $[21,25,26]$. A key motive for selling prescribed methadone is to raise funds to buy other, preferred, drugs or to pay for private prescriptions which cannot be obtained as part of the free provision of care [27]. Common tactics used to obtain excess methadone for illicit sale include acquiring more than one prescription and obtaining a higher dosage than required [28]. The cost of methadone on the illicit market fluctuates according to supply and demand [27].

\section{Protocols for Prescribing and Dispensing Methadone}

Prescribing and dispensing practices can facilitate or hinder the diversion of methadone; overly large dosages and 'take-home' prescriptions have been strongly associated with accelerated diversion [8,29]. Official guidelines for the prescribing and dispensing of methadone in the UK state that measures should be taken to prevent diversion, mainly implementing supervised consumption and prescribing methadone in its oral form $[30,31]$. However variations in prescribing protocols are apparent between UK regions and individual prescribers [32-34] and prescribing often deviates from guidelines [35]. Prescribing and dispensing practices also vary internationally, in terms of the doses of methadone prescribed [36,37] and the use of supervised consumption [38]. Historically, concerns about diversion have been a trigger for increased regulation [35].

\section{Methadone Diversion in Merseyside}

Merseyside (population 1,353,400 in 2010 [39]) is a mixed rural and urban, affluent and deprived, county in the North West of England and it has been identified as a diverse area with relatively high problematic drug use in some parts and not in others [40]. The diversity of the area and its population make it good candidate for a study of this type and findings will be transferable to other areas undertaking methadone maintenance on a large scale. During the 1980s Merseyside saw a 'heroin epidemic' [41]. An inter-agency approach to tackling this major heroin problem using methadone maintenance therapy (MMT) alongside other harm reduction approaches successfully reduced the prevalence of illicit drug use and acquisitive crime, although methadone leakage became a concern [42]. Although models of drug treatment in the UK are becoming more 'recovery' focused, with greater focus on rehabilitation, recovery networks and reintegration [43], MMT remains a key element in the treatment for opiate addiction both nationally and in the region [44]. During the year 2009/ 10, 8,759 drug users accessed general practitioner or specialist prescribing in Merseyside (C. Gibbons, personal communication, February 23, 2011). However methadone diversion remains an issue, with drug users coming into contact with drugs workers in custody suites reporting illicit methadone use via national monitoring systems.

\section{Research Aims}

Further empirical data on the magnitude and trends of the diversion of prescription opioids are needed to inform clinical decisions and risk management $[38,45]$. Little recent published work has investigated the diversion of methadone in England. This research aimed to examine the extent and nature of methadone diversion from the perspective of a large sample of opiate users in Merseyside. Findings will inform drug treatment practitioners and commissioners across the UK as to the mechanics of the market for illicit methadone, to enable them to consider best practice in addressing the issue of diversion with clients. There are difficulties transferring learning on this topic to other countries due to large variations in treatment delivery approach, drugs used and legislation but it is hoped that many aspects of the findings will be of use to practitioners and commissioners involved in the delivery of MMT in other countries with established treatment systems.

\section{Methodology \\ Participants}

Participants were recruited from 28 sites across Merseyside between November 2008 and September 2010. Sites included primary prescribing services (community drugs teams), agencies providing treatment specifically for offenders, service user forums and services providing accommodation for drug users. Recruitment approaches varied from site to site but generally advertising materials were placed in waiting rooms/communal areas or handed out by practitioners indicating when members of the research team would be in attendance. On the designated recruitment days the research team attended the service and approached individuals within communal areas or practitioners directed potential participants to them. Any individual over 18 and who had used methadone (licit or illicit) in the previous year was eligible.

\section{Materials}

A 28 item questionnaire with a mixture of closed and open questions was developed after an examination of 
previous literature and with input from a number of drug treatment practitioners. Topics covered included current prescribing, obtaining and providing methadone, reasons for using illicit methadone and other drug use. No personal details aside from age and gender were collected to ensure confidentiality and reassure participants in an attempt to promote full disclosure. Before commencing the interview all participants were asked to confirm that they had not taken part in the interview previously.

\section{Procedure}

Once participants had indicated their desire to take part in the study they received a full explanation of the project (verbal and written) including assurances around confidentiality and were asked to provide written consent for their participation. The questionnaire was completed by the researcher in an interview with the participants (lasting approximately 15 minutes). Participants received a travel voucher (worth $£ 4$ ) as reimbursement for their time.

\section{Analysis}

All analysis was conducted using PASW Statistics 17.0. The Chi-square test for association was used for comparisons across categorical items (e.g. gender) and independent measures $\mathrm{t}$-tests were applied for continuous data (e.g. age of participants).

\section{Ethics}

The design and procedure of the project, including the questionnaires, were reviewed and approved by both the authors' university ethics committee and a National Health Service Research Ethics Committee.

\section{Results}

\section{Sample Characteristics}

A total of 886 participants were recruited aged between 18 and 64 years old (mean 38, sd 7.03). The majority of the sample were male (71\%). These characteristics are broadly similar to national (England) figures for individuals engaged in treatment in 2009/10 (median age 33, $73 \%$ male) [46]. In 2009/10 the total number of individuals receiving General Practitioner or agency based prescribing in Merseyside was 7,392. The sample represents $12 \%$ of this population or $7 \%$ of the estimated opiate using population within the geography (latest available estimate for 2008/9) [47]. The majority of participants $(86 \%)$ were prescribed methadone at the time of their interview, with all but 29 of the sample prescribed methadone within the past year. Among those participants currently prescribed methadone, $85 \%$ were receiving doses of $80 \mathrm{mg}$ a day or less (28\% of the sample were receiving less than $40 \mathrm{mg}$ a day). Frequent prescription pick-ups were the norm with $72 \%$ of participants picking up daily and $22 \%$ several times a week.

\section{Reasons for using prescribed methadone}

Participants reported a wide variety of reasons for obtaining a prescription, primarily 'to avoid withdrawal' ( $84 \%$ of participants), 'to aid them to achieve abstinence' (22\%), 'to relieve unpleasant mental states e.g. anxiety' (18\%), 'to stabilise their lifestyle' (11\%) or 'to stop them committing crime' (8\%). Regardless of the reasons stated, high levels of satisfaction were reported with prescribed methadone's ability to achieve this goal with only $5 \%$ of participants claiming that methadone was ineffective for their stated expectation.

\section{Supervision}

More than half of the sample (53\%), were not on supervised consumption at the point they were interviewed, so many were in a position to divert their methadone if that was their desire. Among those supervised, $60 \%$ said they would prefer not to be and gave a variety of reasons for this including embarrassment at taking methadone in the chemist, inconvenience and a desire for greater control over the time and location of use including splitting doses (half in the morning and half in the evening). A lack of satisfaction with supervision was significantly associated with clients feeling that the reasons why they were on supervision had not been explained to them fully $(\chi 2=13.23, \mathrm{p}<0.05)$.

\section{Size of the market}

$60 \%$ of participants suggested that at some point in the past year they had obtained illicit methadone whilst $22 \%$ said they had done so in the past four weeks. This identifies the presence of a substantial market for diverted methadone. However, the discrepancy between current (4 wks) and previous (yr) usage, suggests that it is not a market that clients routinely use. Much lower proportions of clients reported providing methadone to others over the same time periods ( $14 \%$ past year, $5 \%$ past 4 wks). It may be that clients were less willing to discuss the provision of their methadone to others for fear that it would prejudice their future treatment despite reassurances to the contrary. Analysis supported this as there was a significant association between where clients were recruited and reports of providing methadone in the previous year $(\chi 2=34.924, \mathrm{p}<0.001)$. A greater proportion of participants recruited outside of their prescribing agency reported providing their methadone to others than those recruited at the agency ( $28 \%$ compared to $11 \%$ ).

The size of the market is also indicated by reports from clients about the number of people they knew who regularly provided or obtained methadone 
illegally; $76 \%$ of participants knew at least one person who provided their methadone to others at least once a month whilst $72 \%$ knew at least one person who obtained illicit methadone at least once a month. For both obtaining and providing methadone more than three in ten participants said they knew more than five people who engaged in this activity at least once a month (Figure 1).

Questions about price revealed that $100 \mathrm{mg}$ of methadone rarely cost more than $£ 10$ (only $3 \%$ of participants reported paying over this amount in the past year).

\section{The nature of the market}

Most diversion of methadone was reported to take place between friends or associates. Very small proportions of participants undertook transactions with an individual they identified as a 'dealer' although where money was exchanged (to either buy or sell methadone) dealers were more commonly reported (however still in a small proportion of cases). When obtaining methadone the market would appear to be split equally into a cash based process ( $43 \%$ of participants had bought methadone in the past year) and a process where methadone, on the surface, is provided for free ( $44 \%$ of participants had been given methadone in the past year). Money was less likely to be involved when participants were providing their methadone to others with $13 \%$ of participants giving away their methadone in the past year compared to $5 \%$ who reported selling it. Participant's reticence to admit monetary gain from the process may in part explain the lower proportions of individuals reporting selling methadone (Table 1).
Clients who obtained methadone in the past year were significantly older than their counterparts who had not obtained methadone $(\mathrm{t}(884)=-2.436, \mathrm{p}<0.05)$. However there was no significant difference in the ages of clients who had or had not provided methadone to others $(t(884)=0.121$, ns). The gender of participants was significantly associated with the provision of methadone in the past year $(\chi 2=4.982, \mathrm{p}<0.05)$ but not with obtaining methadone $(\chi 2=0.016, \mathrm{~ns})$. One in ten female participants $(10 \%)$ reported providing methadone to others in the past year compared to $16 \%$ of males. Participant's perceptions of the effectiveness of their prescribed methadone and their current prescribed dose levels were not significantly associated with obtaining or providing methadone either in the past year or past 4 weeks. Whether participants were currently supervised was significantly associated with obtaining $(\chi 2=10.699$, $\mathrm{p}<0.005)$ and providing methadone $(\chi 2=6.479, \mathrm{p}<$ 0.05 ) in the past year (supervised participants more likely to have obtained methadone but less likely to have provided methadone) and providing methadone in the past four weeks $(\chi 2=7.341, \mathrm{p}<0.01)$ (supervised participants less likely to report providing methadone in the past four weeks) but there was no association between supervision and obtaining methadone in the past 4 weeks $(\chi 2=0.322, \mathrm{~ns})$. Obtaining methadone in the past year $(\chi 2=7.111, \mathrm{p}<0.01)$ and past 4 weeks $(\chi 2=$ $4.481, \mathrm{p}<0.05)$ were also significantly associated with participant's perceptions about the extent to which the aims of their treatment had been explained to them. In both cases clients who felt that the aims of their treatment had not been fully explained to them were more

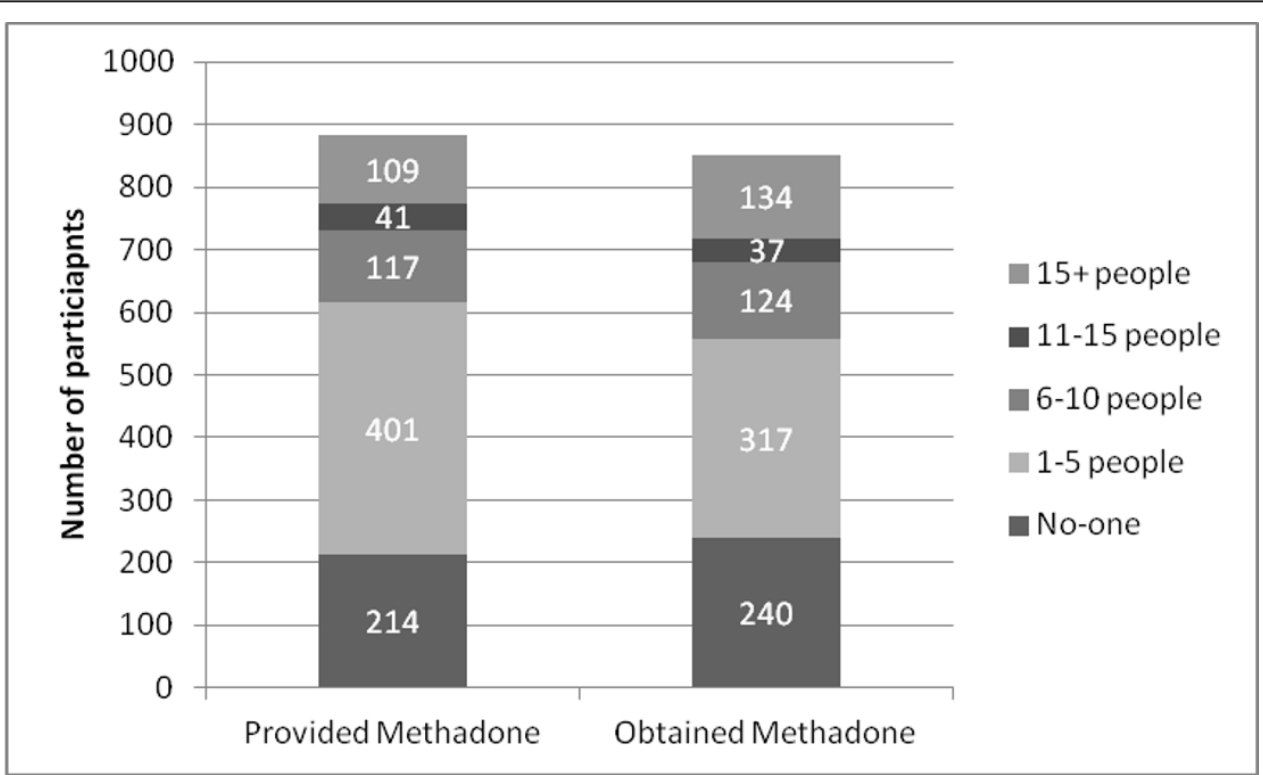

Figure 1 Number of individuals participants knew who regularly provided or obtained methadone illegally. 
Table 1 Numbers of participants reporting diversion activity and who with

\begin{tabular}{|c|c|c|c|c|}
\hline Diversion Activity & Time period & Number (\%) & Who from/to & Number (\%) \\
\hline \multirow[t]{12}{*}{ Been given methadone $(n=885)$} & Past $\mathrm{Yr}$ & $387(44)$ & Friend/Associate & $346(89)$ \\
\hline & & & Partner & $30(8)$ \\
\hline & & & Relative & $9(2)$ \\
\hline & & & Doctor & $2(1)$ \\
\hline & & & Dealer & $10(3)$ \\
\hline & & & Other & $8(2)$ \\
\hline & Past 4 wks & $126(14)$ & Friend/Associate & $112(88)$ \\
\hline & & & Partner & $10(10)$ \\
\hline & & & Relative & $4(4)$ \\
\hline & & & Doctor & $4(3)$ \\
\hline & & & Dealer & 0 \\
\hline & & & Other & $2(2)$ \\
\hline \multirow[t]{12}{*}{ Bought Methadone $(n=884)$} & Past $\mathrm{Yr}$ & $382(43)$ & Friend/Associate & $343(90)$ \\
\hline & & & Partner & $3(1)$ \\
\hline & & & Relative & 0 \\
\hline & & & Doctor & \\
\hline & & & Dealer & $19(5)$ \\
\hline & & & Other & $14(4)$ \\
\hline & Past 4 wks & $131(15)$ & Friend/Associate & $119(91)$ \\
\hline & & & Partner & 0 \\
\hline & & & Relative & 0 \\
\hline & & & Doctor & 0 \\
\hline & & & Dealer & $6(5)$ \\
\hline & & & Other & $3(2)$ \\
\hline \multirow[t]{12}{*}{ Given away methadone $(n=854)$} & Past $\mathrm{Yr}$ & $111(13)$ & Friend/Associate & $84(76)$ \\
\hline & & & Partner & $30(27)$ \\
\hline & & & Relative & $4(4)$ \\
\hline & & & Doctor & 0 \\
\hline & & & Dealer & 0 \\
\hline & & & Other & 0 \\
\hline & Past 4 wks & $35(4)$ & Friend/Associate & $24(69)$ \\
\hline & & & Partner & $11(31)$ \\
\hline & & & Relative & $1(3)$ \\
\hline & & & Doctor & 0 \\
\hline & & & Dealer & 0 \\
\hline & & & Other & 0 \\
\hline \multirow[t]{11}{*}{ Traded methadone $(n=855)$} & Past $\mathrm{Yr}$ & $28(3)$ & Friend/Associate & $27(96)$ \\
\hline & & & Partner & 0 \\
\hline & & & Relative & 0 \\
\hline & & & Doctor & 0 \\
\hline & & & Dealer & $1(4)$ \\
\hline & & & Other & $1(4)$ \\
\hline & Past 4 wks & $9(1)$ & Friend/Associate & $9(100)$ \\
\hline & & & Partner & 0 \\
\hline & & & Relative & 0 \\
\hline & & & Doctor & 0 \\
\hline & & & Dealer & 0 \\
\hline
\end{tabular}


Table 1 Numbers of participants reporting diversion activity and who with (Continued)

\begin{tabular}{|c|c|c|c|c|}
\hline & & & Other & $1(11)$ \\
\hline \multirow[t]{12}{*}{ Sold methadone $(n=854)$} & Past $\mathrm{Yr}$ & $46(5)$ & Friend/Associate & $43(93)$ \\
\hline & & & Partner & $1(2)$ \\
\hline & & & Relative & 0 \\
\hline & & & Doctor & 0 \\
\hline & & & Dealer & 0 \\
\hline & & & Other & $3(7)$ \\
\hline & Past 4 wks & $14(2)$ & Friend/Associate & 14(100) \\
\hline & & & Partner & 0 \\
\hline & & & Relative & 0 \\
\hline & & & Doctor & 0 \\
\hline & & & Dealer & 0 \\
\hline & & & Other & 0 \\
\hline
\end{tabular}

likely to report that they had obtained methadone illicitly (Table 2).

\section{Discussion}

Rates of methadone diversion or use of diverted methadone seen in this study indicate the presence of a relatively large active 'black market' for methadone which a substantial proportion of participants had utilised but in general not regularly, evidenced by the differences between proportions of clients reporting obtaining illicit methadone in the past year compared to past four weeks. This suggests that there are specific circumstances under which this occurs. Due to different populations, national policies and time frames, comparisons of rates of use identified in this study with those from other countries are difficult. Among opiate users in New
York studies have shown high rates of lifetime illicit methadone use (53\% [48] and 72\% [14]), and relatively high recent use $(21.3 \%$ in the previous 6 months) [48]. Among a population of heroin users in Montreal, $42 \%$ had used illicit methadone in the previous 6 months [19]. In Dublin, 73\% of opiate users presenting for treatment had used illicit methadone and 55\% used at least once whilst in treatment [25]. In Australia among a sample presenting for drug treatment, $51 \%$ had used methadone illicitly in the year before presentation [24]. Comparisons with other geographies can also prove difficult due to the differing levels of 'treatment penetration'. Areas where access to treatment is relatively easy with short waiting times would be assumed to have less need for drug users to turn to the use of street drugs or to diverted methadone thereby minimising the market.

Table 2 Interaction of individual factors with diversion activity

\begin{tabular}{|c|c|c|c|c|c|}
\hline Factor & & $\begin{array}{l}\text { Obtained methadone } \\
\text { in past year }\end{array}$ & $\begin{array}{l}\text { Obtained methadone } \\
\text { in past } 4 \text { weeks }\end{array}$ & $\begin{array}{l}\text { Provided Methadone } \\
\text { in past year }\end{array}$ & $\begin{array}{l}\text { Provided methadone in } \\
\text { past } 4 \text { weeks }\end{array}$ \\
\hline & & Number & Number & Number & Number \\
\hline \multirow[t]{2}{*}{ Gender } & Male $(n=631)$ & 379 & 132 & 98 & 37 \\
\hline & Female $(n=255)$ & 152 & 66 & $25^{*}$ & 4 \\
\hline \multirow{2}{*}{$\begin{array}{l}\text { Is methadone } \\
\text { effective }\end{array}$} & Yes $(n=725)$ & 410 & 149 & 88 & 37 \\
\hline & No $(n=40)$ & 25 & 11 & 7 & 4 \\
\hline \multirow[t]{2}{*}{ Dose Level } & $\begin{array}{l}\text { High (above } 80 \text { mg/ } \\
\text { day) }(n=113)\end{array}$ & 71 & 31 & 19 & 9 \\
\hline & $\begin{array}{l}\text { Low (below } 80 \mathrm{mg} / \\
\text { day) }(n=650)\end{array}$ & 363 & 129 & 75 & 32 \\
\hline \multirow[t]{2}{*}{ Currently Supervised } & Yes $(n=362)$ & 228 & 79 & 33 & 11 \\
\hline & No $(n=402)$ & $206^{* * *}$ & 81 & $61^{*}$ & $30^{* *}$ \\
\hline \multirow{2}{*}{$\begin{array}{l}\text { Aims of treatment } \\
\text { fully explained }\end{array}$} & Yes $(n=652)$ & 358 & 128 & 76 & 34 \\
\hline & No $(n=111)$ & $76^{* *}$ & $32^{*}$ & 18 & 7 \\
\hline
\end{tabular}

*Significant at $p<0.05,{ }^{* *}$ Significant at $p<0.01,{ }^{* *}$ Significant at $p<0.005$ 
Merseyside like many parts of the UK has good access to prescribing with short waiting times therefore it could be assumed this is not a major driver for the size of the diverted methadone market.

The reportedly low price of illicit methadone in Merseyside (as seen in other research [24]) suggests that there is a large enough supply in the market to keep this price low [49-51].

A large proportion of clients reported being prescribed under the optimal dose levels recommended in the UK guidelines on clinical management of drug use and dependence [30] which are suggested to be $60-120 \mathrm{mg}$ a day. A phenomenon of under prescribing is not unique to the UK having been reported in a number of other countries [52,53]. There is a considerable body of evidence that higher doses are associated with more positive treatment outcomes [36,54-59] and doses over 100 $\mathrm{mg}$ of methadone have been associated with more positive outcomes in terms of tests for illicit opiates [60]. So the 'topping up' that has been seen in this study and in others [26] may be associated with the relatively low levels of prescribing reported by participants. However, high levels of satisfaction with the effectiveness of methadone in achieving participant's stated reasons for using methadone and a lack of association between perceptions of effectiveness or dose levels and diversion suggest that it is not a lack of efficacy of prescribed methadone that is a driver for the illicit market. This supports findings from other work [26] which indicated that adequacy of dose was not related to levels of illicit methadone use. The impact of prescribing higher doses of methadone in terms of clients' potential desire (and the desire of the current UK Government) to move towards abstinence as soon as possible also requires some consideration. Higher doses may lead to greater dependency on methadone and subsequent longer, more difficult periods of detoxification.

High proportions of clients on supervised consumption reporting dissatisfaction with this status raises some potential issues with disengagement from services, especially if reasons for not liking supervision are as emotive as embarrassment due to the locality of chemists or the lack of appropriate private consumption rooms [61] which are critical in clients satisfaction with supervised consumption [62]. Also within the framework of the current UK focus on recovery [43] with clients being reintegrated into mainstream society as quickly as is safe, factors such as inconvenience and a lack of control over prescribing have potential to disempower drug users seeking to make positive changes [63-65]. However, this must be balanced against the health risks posed by unregulated use of methadone in the community both to individuals already prescribed, those not engaging with services and non drug users [66-68].
Previous work has suggested that taking the opposite approach, starting unsupervised and moving to supervised when concerns around appropriate use become apparent, can lead to greater attrition [69]. Disempowerment and disengagement are also potential outcomes if clients feel that they are not a part of their treatment planning $[44,70]$ and, in this study, participants who felt that they had not had the aims of their treatment explained were more likely to report 'topping up' their methadone prescription. In addition levels of satisfaction with being on supervised consumption were associated with the degree to which participants felt the reasons for this had been explained to them fully.

The desire for additional control over when and how methadone could be taken e.g. some in the morning and some in the afternoon, may be linked to participants anxiety about the ability of their methadone to hold them for the full $24 \mathrm{hrs}$ [71] despite the fact that as long as dosing is correct the pharmacology of methadone should mean this presents no problem. This may link again though to the relatively low doses being prescribed, although as outlined most participants found that their methadone was effective for their purposes.

Supervised consumption was associated with lower levels of past year and past four week diversion implying that having this control in place is effective, despite doubts expressed by drug treatment agency key workers in Merseyside [27]. Findings support previous work indicating that supervised consumption can promote adherence to prescribed methadone use [72]. The high frequency of pick-ups reported should also mean that individuals do not have large quantities to pass on at any one time, unless they are stockpiling, and should help to guarantee adherence to treatment [72].

The methadone market does not appear to be commercially motivated with most diversion happening between friends or associates (not with 'dealers') and often with no money changing hands, suggesting a considerable altruistic element or the expectation of reciprocation in the future. It may also be indicative of a process of self medication among drugs users. Clients who are self titrating (only by small amounts at a time) will have small amounts of methadone left over which are then available to friends and associates. Despite this non commercial profile legal considerations remain. Individuals caught with someone else's prescription or caught passing their prescription to another person could face substantial criminal sanctions (methadone is controlled under Class A of the Misuse of Drugs Act 1971 with a potential sentence of up to life in prison for an offence of supply or seven years for possession). In reality the risk of detection may be relatively small and it is not clear that in all cases criminal justice agencies would apply the full measure of the law. In addition this 
level of risk may be little disincentive to individuals intent on doing so and who are likely to have an existing criminal record. Despite this it may be prudent for practitioners to emphasise this potential consequence of diversion along with clinical aspects e.g. overdose [9-12].

It is not clear why older participants should be more likely to report obtaining illicit methadone in the past year. It may be that these individuals are more likely to have received methadone treatment previously, in the past have had more reason to utilise the market for methadone [26] and know other drug users who have access to methadone when compared to younger clients who may not have been prescribed in the past. From the data collected for this study it is not clear why females should be less likely to provide methadone to others than males. It may reflect a number of factors including; greater risks perceived by this group in terms of the impact on dependants if they were caught providing methadone (and an associated fear of revealing diversion); a higher perceived need for treatment among this group (previous studies have suggested females are more likely to use street methadone possibly indicating an increased need for treatment [20] or greater levels of motivation for recovery. Unfortunately this is not an area that has been investigated in previous work on methadone diversion. It is a point that will need to be tackled in future research.

\section{Study Limitations}

The possibility of underreporting particularly among participants recruited within prescribing agencies must be considered (as seen from findings where individuals recruited outside prescribing agencies reported higher levels of diversion and use of the diverted methadone). In particular clients who are diverting their methadone on a large scale are unlikely to agree to discuss this with a researcher who is asking about methadone diversion. Removal of this under reporting would only serve to increase the suggested size of the market which is already assessed as being considerable. The potential reticence of participants to discuss diversion with an independent researcher, who has no involvement with the delivery of treatment raises questions about the extent to which clients would report any diversion to clinicians. As practitioners have reported that objective measures to detect diversion (e.g. drug testing) are not effective [61] subjective judgements must be relied upon which are not reliable and if action is based on these it is likely to cause conflict.

Measures to ensure that individuals felt comfortable discussing a sensitive topic such as collecting the bare minimum of personal details may introduce the possibility that participants were interviewed twice. A small group of interviewers and the use of a filter question to determine prior completion should have minimised this issue.

This sample in this study was mostly of a group that have been engaged with treatment relatively recently, further investigation with opiate users not in contact with treatment is required to better understand the experiences of this group as potential consumers of diverted methadone. However, as a general rule a number of those clients engaged in treatment must at some point be the suppliers of methadone so their perception of individuals involved in the market can be considered accurate.

\section{Conclusions}

Whilst there continues to be a considerable market for diverted methadone, opiate users would generally appear to make use of it relatively infrequently. Supervision would appear to be an appropriate measure for controlling diversion, however the potential effect of its long term imposition on a client's recovery journey should be considered especially as long term restrictions on take home doses have been shown to impede treatment engagement $[73,74]$. The market is characterised as much altruism as by commercial motivation but the health and criminal justice risks posed by diversion to individuals attempting to tackle their addiction remain considerable. Treatment agencies need to emphasise these risks whilst ensuring that treatment aims are effectively shared with clients to ensure adherence to treatment.

\section{Acknowledgements}

The authors would like to thank those who contributed to this paper, by providing valuable input into the research design and materials (in particular Debbie Holt and David Young), the fieldwork team and the agencies who supported recruitment.

\section{Author details}

${ }^{1}$ Criminal Justice System Manager, Centre for Public Health, Liverpool John Moores University, $2^{\text {nd }}$ Floor, Henry Cotton Campus, 15-21 Webster Street, Liverpool, L3 2ET, UK. ${ }^{2}$ Researcher in Substance Misuse, Centre for Public Health, Liverpool John Moores University, $2^{\text {nd }}$ Floor, Henry Cotton Campus, 15-21 Webster Street, Liverpool, L3 2ET, UK.

\section{Authors' contributions}

PD conceived of the study, participated in its design, conducted the analysis and produced the final manuscript. HB led on the design and co-ordination of the study (including fieldwork), conducted and wrote the literature review. All authors have read and approved the final manuscript.

\section{Competing interests}

The authors declare that they have no competing interests.

Received: 28 September 2011 Accepted: 13 January 2012

Published: 13 January 2012

\section{References}

1. Van Ameijden E, Langendam E, Coutinho R: Dose-effect relationship between overdose mortality and prescribed methadone dosage in lowthreshold maintenance programs. Addict Behav 1999, 24:559-563. 
2. Risser D, Honigschnabl S, Stichenwirth M, Pfudl S, Sebald D, Kaff A, Bauer G: Mortality of opiate users in Vienna, Austria. Drug Alc Depend 2001, 64:251-256.

3. King VL, Stoller KB, Hayes M, Umbricht A, Currens M, Kidorf MS, Carter JA, Schwartz $\mathrm{R}$, Brooner RK: A multicenter randomized evaluation of methadone medical Maintenance. Drug Alc Depen 2002, 65:137-148.

4. Farre M, Mas A, Torrens M, Moreno V, Cami J: Retention rate and illicit opioid use during methadone maintenance interventions: a metaanalysis. Drug Alc Depen 2002, 65:283-290.

5. Gossop M, Stewart D, Browne N, Marsden J: Methadone treatment for opiate dependent patients in general practice and specialist clinic settings: outcomes at 2-year follow-up. Journal of Substance Abuse Treatment 2003, 24:313-321.

6. Neale J: Methadone, methadone treatment and non-fatal overdose. Drug Alc Depend 2000, 58:117-124.

7. Weinrich M, Stuart M: Provision of methadone treatment in primary care medical practices: review of the Scottish experience and implications for US policy. JAMA 2000, 283:1343-8.

8. Heinemann A, Iwersen-Bergmann S, Stein S, Schmoldt A, Püschel K: Methadone-related fatalities in Hamburg 1990-1999: implications for quality standards in maintenance treatment? Forensic Sci Int 2000 113:449-455.

9. Seymour A, Black M, Jay J, Cooper G, Weir C, Oliver J: The role of methadone in drug-related deaths in the west of Scotland. Addiction 2003, 98:995-1002.

10. Corkery J, Schifano F, Ghodse H, Oyefeso A: The effects of methadone and its role in fatalities. Hum Psychopharm Clin 2004, 19:565-576.

11. Graham NA, Merlo LJ, Goldberger BA, Gold MS: Methadone- and heroinrelated deaths in Florida. Am J Drug Alcohol Ab 2008, 34:347-53.

12. Madden ME, Shapiro SL: The Methadone Epidemic: Methadone-Related Deaths on the Rise in Vermont. Am J Foren Med and Path 2011, 32:131-135.

13. Neale J: Drug users' views of substitute prescribing conditions. Int J of Drug Policy 1999, 10:247-258

14. Davis W, Johnson B: Prescription opioid use, misuse, and diversion among street drug users in New York City. Drug and Alcohol Dependence 2008, 92:267-276.

15. Mitchell SG, Kelly SM, Brown BS, Schacht Reisinger H, Peterson JA, Ruhfa A, Agar MH, O'Grady KE, Schwartz RP: Uses of diverted methadone and buprenorphine by opioid addicted individuals in Baltimore, Maryland. The Am J Addiction 2009, 18:346-355.

16. Dasgupta N, Bailey EJ, Cicero T, Inciardi J, Parrino M, Rodenblum A, Dart RC: Post-marketing surveillance of methadone and buprenorphine in the United States. Pain Medicine 2010, 11:1078-1091.

17. Hoare J, Moon D: Drug misuse declared: findings from the $2009 / 10$ British Crime Survey: England and Wales. London: Home Office; 2010.

18. Winstock AR, Lea T, Sheridan J: Prevalence of diversion and injection of methadone and buprenorphine among clients receiving opioid treatment at community pharmacies in New South Wales, Australia. Int J Drug Policy 2008, 19:450-458.

19. Lauzon P, Vincelette J, Bruneau J, Lamothe F, Lachance N, Brabant M, Soto J: Illicit use of methadone among IV drug users in Montreal. J Subst Abuse Treat 1994, 11:457-461.

20. Vlahov D, O'Driscoll P, Mehta SH, Ompad DC, Gern R, Galai N, Kirk GD: Risk factors for methadone outside treatment programs: implications for HIV treatment among injection drug users. Addiction 2007, 102:771-777.

21. Fountain J, Griffiths P, Farrell M, Gossop M, Strang J: Benzodiazepines in polydrug-using repertoires: the impact of the decreased availability of temazepam gel-filled capsules. Drug-Educ Prev Polic 1999, 6:61-69.

22. Sunjic S, Howard J: "Non injectables": methadone syrup and benzodiazepine injection by methadone-maintained clients. Drug Alc Rev 1996, 15:245-250.

23. Gossop M, Marsden J, Stewart D, Treacy S: Routes of drug administration and multiple drug misuse: regional variations among clients seeking treatment at programmes throughout England. Addiction 2000, 95:1197-1206

24. Winstock AR, Lea T: Diversion and injection of methadone and buprenorphine among clients in public opioid treatment clinics in New South Wales, Australia. Subst Use Misuse 2010, 45:240-52.
25. Roche A, McCabe S, Smyth BP: Illicit methadone use and abuse in young people accessing treatment for opiate dependence. Eur Addict Res 2008, 14:219-25.

26. Best D, Harris J, Gossop M, Farrell M, Finch E, Noble A, Strang J: Use of non-prescribed methadone and other illicit drugs during methadone maintenance treatment. Drug Alcohol Rev 2000, 19:9-16.

27. Fountain J, Strang J, Gossop M, Farrel M, Griffiths P: Diversion of prescribed drugs by drug users in treatment: analysis of the UK market and new data from London. Addiction 2000, 95:393-406.

28. Fountain J, Griffiths P, Farrell M, Gossop M, Strang J: Diversion tactics: how a sample of drug misusers in treatment obtained surplus drugs to sell on the illicit market. Int J of Drug Policy 1997, 9:159-167.

29. Edmunds M, Hough M, Urquía N: Tackling local drug markets. London: Home Office; 1996

30. Department of Health (England) and the devolved administrations: Drug misuse and dependence: UK guidelines on clinical management. London: Department of Health (England), the Scottish Government, Welsh Assembly Government and Northern Ireland Executive; 2007.

31. National Institute for Health and Clinical Excellence: Methadone and buprenorphine for the management of opioid dependence. London, NICE; 2007.

32. Matheson C, Bond C, Hickey F: Prescribing and dispensing for drug misusers in primary care: current practice in Scotland. Fam Prac 1999 16:375-379.

33. Strang J, Sheridan J: Methadone prescribing to opiate addicts by private doctors: comparison with NHS practice in south east England. Addiction 2001, 96:567-576.

34. Strang J, Sheridan J, Hunt C, Kerr B, Gerada C, Pringle M: The prescribing of methadone and other opioids to addicts: national survey of GPs in England and Wales. Br J of Gen Prac 2005, 55:444-451.

35. Bell J: The global diversion of pharmaceutical drugs: opiate treatment and the diversion of pharmaceutical opiates: a clinician's perspective. Addiction 2010, 105:1531-1537.

36. Mohamad N, Hidayah Abu Bakar N, Musa N, Talib N, Ismail R: Better retention of Malaysian opiate dependents treated with high dose methadone in methadone maintenance therapy. Harm Reduct J 2010, 7:30.

37. Chunging $L$, Roger D: A qualitative study exploring the reason for low dosage of methadone prescribed in the MMT clinics in China. Drug Alcohol Depen

38. Hall W, Degenhardt L: Regulating opioid prescribing to provide access to effective treatment while minimizing diversion: an overdue topic for research. Addiction 2007, 102:1685-1688.

39. Office for National Statistics: Mid year population estimates 2010: 30/06/ 11. London: ONS; 2011

40. Hay G, Gannon M, MacDougall J, Millar T, Eastwood C, McKeganey N: Estimates of the prevalence of opiate use and/or crack cocaine use (2006/07). London: Home Office; 2008.

41. Parker $H$, Newcombe R: Heroin Use and Acquisitive Crime in an English Community. Br J Sociol 1987, 38:331-350.

42. Parker H, Kirby P: Methadone Maintenance and Crime Reduction on Merseyside. London: Home Office Police Research Group; 1996.

43. Home Office: Drug strategy 2010: reducing demand, restricting supply, building recovery: supporting people to live a drug free life. London: Home Office; 2010.

44. Strang J: Recovery-orientated drug treatment: an interim report. London, National Treatment Agency; 2011.

45. Inciardi JA, Surratt HL, Kurtz SP, Cicero TJ: Mechanisms of prescription drug diversion among drug-involved club- and street-based populations. Pain Med 2007, 8:171-183.

46. The National Treatment Agency for Substance Misuse: Statistics from the National Drug Treatment Monitoring System (NDTMS) 1 April 2009 - 31 March 2010. London: The National Treatment Agency for Substance Misuse; 2010.

47. Hay G, Gannon M, Casey J, Millar M: Estimates of the prevalence of opiate use and/or crack cocaine use (2008/09) North West Region. London: Home Office; 2009

48. Colon HM, Robles RR, Deren S, Sahai H, Finlinson HA, Andia J, Cruz MA, Kang SY, Oliver-Velez D: Between-city variation in frequency of injection 
among Puerto Rican injection drug users: East Harlem, New York, and Bayamon, Puerto Rico. J Acquir Immune Defic Syndr 2001, 27:405-413.

49. Caulkins JP, Reuter P, lguchi MY, Chiesa J: How goes the war on drugs? An assessment of US drug problems and policy. Santa Monica: RAND; 2005.

50. Wilson L, Stevens A: Understanding drug markets and how to influence them. The Beckley Foundation Drug Policy Programme Report 14 London: Beckley Foundation; 2007.

51. Schifano F, Corkery J: Cocaine/crack cocaine consumption, treatment demand, seizures, related offences, prices, average purity levels and deaths in the UK (1990-2004). J Psychopharmacol 2008, 22:71-79.

52. Pollack HA, D'Aunno T: Dosage Patterns in Methadone Treatment: Results from a National Survey, 1988-2005. Health Serv Res 2008, 43:2143-2163.

53. Lin C, Detels R: A qualitative study exploring the reason for low dosage of methadone prescribed in the MMT clinics in China. Drug Alc Depend 2011, 117:45-49.

54. McGlothlin WH, Anglin MD: Long-term follow-up of clients of high- and low-dose methadone programs. Arch Gen Psychiatr 1981, 38:885-892

55. Joe GW, Simpson DD, Hubbarb RL: Treatment predictors of tenure in methadone maintenance. J Subst Abuse 1991, 3:73-84.

56. Caplehorn JRM, McNeil DR, Klienbaum DG: Clinic policy and retention in methadone maintenance. Int J Addict 1993, 28:73-89.

57. Strain EC, Stitzer ML, Liebson IA, Bigelow GE: Methadone dose and treatment outcome. Drug Alc Depend 1993, 33:105-117.

58. Strain EC, Bigelow GE, Liebson IA, Stitzer ML: Moderate- vs High-Dose Methadone in the Treatment of Opioid Dependence A Randomized Trial. JAMA 1999, 281:1000-1005.

59. Faggiano F, Vigna-Taglianti F, Versino E, Lemma P: Methadone maintenance at different dosages for opioid dependence. Cochrane Database of Systematic Reviews 2003, 3: CD002208.

60. Fareed A, Casarella J, Roberts M, Sleboda M, Amar R, Vayalapalli S, Drexler K: High Dose versus Moderate Dose Methadone Maintenance: Is There a Better Outcome? J Addict Dis 2009, 28:399-405.

61. Baldwin HF, Duffy P: Stakeholders' Perceptions of Methadone Diversion and their Responses to it. Int J of Drug Policy

62. Stone E, Fletcher R: User views on supervised methadone consumption. Addict Bio 2003, 8:45-48.

63. Pani PP, Pirastu R, Ricci A, Gessa G L: Prohibition of take home dosages: Negative consequences on methadone maintenance treatment. Drug A/C Depend 1996, 41:81-84.

64. White JM, Ryan C F, Ali RL: Improvements in retention rates and changes in client group with methadone maintenance streaming. Drug Alc Rev 1996, 15:83-88.

65. Ritter A, Di Natale R: The relationship between take-away methadone policies and methadone diversion. Drug Alc Rev 2005, 24:347-352.

66. Beattie J: Children Poisoned with Illegal Drugs in Glasgow. BMJ 1999, 318:1137.

67. Li L, Levine B, Smialek JE: Fatal Methadone Poisoning in Children: Maryland 1992-1996. Subst Use Misuse 2000, 35:1141-1148.

68. Strang J, Hall W, Hickman M, Bird SM: Impact of supervision of methadone consumption on deaths related to methadone overdose (1993-2008): analyses using OD4 index in England and Scotland. BMJ 2010, 341:4851.

69. Bell JR, Ryan A, Mutch C, Batey R, Rea F: Optimising the benefits of unobserved dose administration for stable opioid maintenance patients: Follow-up of a randomised trial. Drug Alcohol Depen 2008, 96:183-186.

70. Ernst DB, Pettinati HM, Weiss RD, Donovan DM, Longabaugh R: An Intervention for Treating Alcohol Dependence: Relating Elements of Medical Management to Patient Outcomes With Implications for Primary Care. Ann Fam Med 2008, 6:435-440.

71. Tacke $U$, Wolff $K$, Finch $E$, Strang J: The effect of tobacco smoking on subjective symptoms of inadequacy ("not holding") of methadone does among opiate addicts in methadone maintenance treatment. Addict Biol 2001, 6:137-145.

72. Haskew M, Wolff K, Dunn J, Bearn J: Patterns of adherence to oral methadone: Implications for prescribers. J Subst Abuse Treat 2008, 35:109-115.

73. Deering DEA, Sheridan J, Sellman JD, Adamson SJ, Pooley S, Robertson R, Henderson C: Consumer and treatment provider perspectives on reducing barriers to opioid substitution treatment and improving treatment attractiveness. Addict Behav 2011, 36:636-642.
74. Stone $E$, Fletcher $K$ : User views on supervised methadone consumption. Addict Biol 2003, 8:45-8.

doi:10.1186/1477-7517-9-3

Cite this article as: Duffy and Baldwin: The Nature of Methadone Diversion in England: A Merseyside case study. Harm Reduction Journal 2012 9:3.

\section{Submit your next manuscript to BioMed Central and take full advantage of:}

- Convenient online submission

- Thorough peer review

- No space constraints or color figure charges

- Immediate publication on acceptance

- Inclusion in PubMed, CAS, Scopus and Google Scholar

- Research which is freely available for redistribution

Submit your manuscript at www.biomedcentral.com/submit
Ciomed Central 